\title{
Nuts, body weight and insulin resistance
}

\author{
Sujatha Rajaram* and Joan Sabaté \\ Department of Nutrition, School of Public Health, Loma Linda University, Loma Linda, CA 92350, USA
}

\begin{abstract}
Traditionally, nuts have been considered a staple food, but because of their high energy and fat content are not considered good for body weight control or insulin sensitivity. Frequent consumption of nuts reduces the risk of coronary artery disease and type- 2 diabetes and nut-enriched diets favourably alter blood lipids in normal and hypercholesterolemic individuals under controlled and free-living dietary conditions. However, whether or not frequent consumption of nuts can cause weight gain and impair insulin sensitivity is not fully understood. Review of the available data to date suggests that adding nuts to habitual diets of free-living individuals does not cause weight gain. In fact, nuts have a tendency to lower body weight and fat mass. In the context of calorie-restricted diets, adding nuts produces a more lasting and greater magnitude of weight loss among obese subjects while improving insulin sensitivity. Further studies are needed to clarify the effect of long-term ( $\geq$ year) consumption of nuts on body weight and their role in altering insulin sensitivity both in normal and type-2 diabetics. In the meantime, there is sufficient evidence to promote the inclusion of nuts as part of healthy diets.
\end{abstract}

Nuts: Body weight: Insulin resistance: Obesity: Body fat

Traditionally, nuts have been used as a staple food for providing energy, protein, essential fatty acids and a host of vitamins and minerals. At the same time, since nuts are energy dense high fat foods, they have not been considered good for controlling body weight and improving insulin sensitivity. While the research on the role of nuts in body weight control and insulin resistance is relatively new, their cardio-protective benefits have been well established. In fact, the current recommendations by the American Heart Association (Krauss et al. 2000) for a heart-healthy diet include nuts as one of the desirable foods to improve blood lipid profile. To date, four large epidemiological studies (Fraser et al. 1992; Kushi et al. 1996; Hu et al. 1998; Albert et al. 2002) have shown that frequent consumption of nuts lowers the risk of fatal and non-fatal coronary heart disease even after adjusting for known coronary risk factors such as age, smoking, sex, family history of hypertension, body weight, physical activity and the intake of other protective foods. More recently, the Nurses Health Study demonstrated that frequent consumption of nuts is inversely related to the risk of type-2 diabetes (Jiang et al. 2002). Besides population based observations, several intervention studies with different kinds of nuts in well-controlled dietary conditions (Sabaté et al. 1993, 2003; Curb et al. 2000; Rajaram et al. 2001; Iwamoto et al. 2002; Sabaté, 2003) or in free living individuals on selfselected diets (Spiller et al. 1992; Abbey et al. 1994; Colquhoun et al. 1996; Chisholm et al. 1998; Spiller et al. 1998; Durak et al. 1999; Edwards et al. 1999; Morgan \& Clayshulte, 2000; Zambon et al. 2000; Almario et al. 2001; Hyson et al. 2002; Jenkins et al. 2002; Lovejoy et al. 2002; Morgan et al. 2002; Garg et al. 2003) have shown that nuts improve blood lipid parameters in both men and women with normal and hypercholesterolemia.

With the steady increase in the incidence of obesity and related chronic diseases, it becomes important to both scientists and health professionals to understand the role of nuts in body weight regulation (Garcia-Lorda et al. 2003; Sabaté, 2003; St-Onge, 2005) and insulin resistance. This review summarizes the data available to date by looking at three lines of evidence: (1) Data from population based studies on the association between nut intake and body weight and insulin resistance; (2) Data from nut intervention studies under controlled and free-living conditions with chronic disease risk factors as the primary outcome; and (3) Data from nut intervention trials with body weight outcome both in free-living healthy subjects and in the context of weight loss in obese individuals. Some of the potential mechanisms by which nuts may influence body weight and insulin resistance are also provided, followed by concluding remarks.

\section{Nuts and body weight \\ Epidemiologic evidence}

There is no epidemiological data to support the concern that nuts may cause weight gain. In Mediterranean countries where the per capita consumption of nuts is almost double that in the United States, the rate of obesity is significantly lower (Sabaté, 1993). A cross-sectional study of 800 schoolgirls in Spain found no differences in body weight in the various categories of nut intake ranging from zero to daily intake (Soriguer et al. 1995). In fact, Mediterranean dietary patterns, of which nuts are an integral part, have been inversely associated with BMI and obesity (Schroder et al. 2004). In the United States, data from the Continuing Survey of Food Intakes by Individuals (US Department of Agriculture \& Agricultural Research Service, 2000) showed no association between nut intake and body mass index (BMI). In this 
survey, the nut-eater group consisted of individuals that reported consumption of tree nuts, peanuts or seeds on any of the 2 days in which the 24-hour recalls were collected. Data from the 1994-6 survey showed that young and adult nut eaters had lower BMI compared to non nut-eaters in spite of higher energy intake among nut eaters. Also, among the nut eaters, the amount of nuts and seeds in their diets did not relate to BMI (Sabaté, 2003).

Large cohort studies that reported a decrease in the risk of coronary artery disease (CAD) with frequent consumption of nuts all show an inverse or no relationship between frequency of nut intake and BMI. In the Adventist Health Study (Fraser et al. 1992), a statistically significant negative effect was seen between consumption of nuts and BMI in a cohort of 31200 subjects, suggesting that those who ate nuts more often were leaner than those who ate nuts infrequently. In addition, a substantial reduction in CAD risk was observed among both lean and obese subjects in this prospective study, with a $\sim 50 \%$ risk reduction for individuals with either low or high BMI consuming nuts $\geq 5$ times/wk compared to their counterparts consuming nuts $\leq 1$ time/wk (Fig. 1). The Nurses Health Study (Hu et al. 1998) also observed a negative association between nut consumption and BMI among 86000 female subjects and a similar cardio-protective effect of nuts in both obese and lean individuals. The Physicians' Health Study (Albert et al. 2002) did not report any association between BMI and nut intake and the BMI's by quartile of nut consumption were very similar. More recently, in a large cohort of women that were followed up for 16 years, the average weight change according to frequency of nut consumption (never to $\geq 5$ times a week), after adjusting for potential confounders, was not significantly different (Kushi et al. 1996). The results of these epidemiological findings indicate an inverse or no relationship between frequent nut consumption and BMI.

\section{Intervention studies with nuts}

\section{Nut feeding studies with CAD risk factors as primary outcome}

Several nut-feeding studies have been conducted to date with the primary objective of measuring cardiovascular disease risk outcomes. These differ in methodological and dietary rigor,

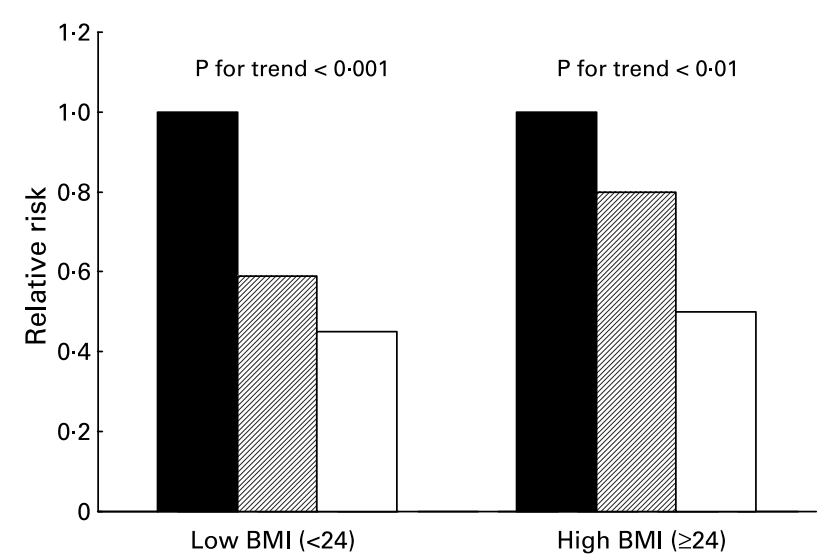

Fig. 1. Age- and sex-adjusted relative risks of coronary artery disease at three nut intakes. ( $\square,<1$ time/week; $1-4$ times/week; $\square, \geq 5$ times/week) according to BMI $\left(\mathrm{kg} / \mathrm{m}^{2}\right)$ in the Adventist Health Study. Reproduced with permission from Fraser et al. (1992). macronutrient composition, especially with respect to the proportion of the different fatty acid in the diets, duration of intervention, subject characteristics and sample size. Collectively, these studies show that nuts lower cholesterol and are therefore recommended as part of heart-healthy diets. None of these studies were set up to look at differences in body weight, because by design the diets in many of the studies, especially the metabolic feeding studies, were controlled and adjusted according to body weight changes.

In the controlled crossover nut intervention studies conducted by our research group, with walnuts, pecans and almonds (Sabaté et al. 1993; Rajaram et al. 2001; Sabaté et al. 2003), two isoenergetic diets (nut diet and the control diet) were tested for their effects on blood lipids and lipoproteins. In these studies, subjects were weighed daily during the 2 -week run-in period and once a week thereafter through the remainder of the study. Caloric intake of the subjects was adjusted to ensure that they neither gained nor lost weight. Based on our observations, when subjects were on the nut diet they tended to lose weight and some reported to being hungry. Hence, their caloric intake was increased in order to prevent weight loss. Using a similar study design, others have also shown that walnuts (Iwamoto et al. 2002) and macadamia nuts (Curb et al. 2000) do not cause changes in body weight when the total energy in the experimental diets are continually adjusted.

Most of the less controlled dietary intervention studies (Table 1) that involved self-selected diets to which a nut supplement was added, also do not report any weight gain with nut consumption. In fact, some of them observed a non-significant tendency to lower weight while subjects were on the nut supplement (Spiller et al. 1992; Abbey et al. 1994; Colquhoun et al. 1996; Zambon et al. 2000; Garg et al. 2003). Three of them observed no differences in body weight in spite of a total increase in energy intake in the nut diet. In one of these studies (Morgan \& Clayshulte, 2000), adding a $68 \mathrm{~g}$ pecan supplement for 8 weeks increased the total energy intake by $\sim 72 \mathrm{~kJ}$ ( $300 \mathrm{kcal})$ and yet both BMI and body weight remained unaffected except in two female subjects who showed a non-significant increase of less than $1 \mathrm{~kg}$. In the other two studies (Almario et al. 2001; Morgan et al. 2002), adding $48 \mathrm{~g}$ or $64 \mathrm{~g}$ walnuts to the habitual diet of hypercholesterolemic patients for 6 weeks increased energy intake by $\sim 86 \mathrm{~kJ}(360 \mathrm{kcal})$ and $\sim 67 \mathrm{~kJ}(280 \mathrm{kcal})$, respectively, with no change in body weight. On the other hand, two studies noted an increase in body weight with nut consumption. The first one (Durak et al. 1999) showed that adding $1 \mathrm{~g} / \mathrm{kg}$ body weight $/ \mathrm{d}$ of hazelnuts to normocholesterolemic subjects increased the mean body weight by $0.5 \mathrm{~kg}$. However, this study was not controlled and non-randomized with no report of energy intake in the nut group compared to baseline. The second (Lovejoy et al. 2002) was on normal weight subjects who added $100 \mathrm{~g}$ almonds to their daily diet for 4 weeks. An increase in body weight of $0.9 \mathrm{~kg}$ in men and $0.3 \mathrm{~kg}$ in women was noted. However, this study did not have a control group and there was an increase in energy intake by $\sim 48 \mathrm{~kJ}$ when nuts were added to the diet. Overall, these studies demonstrate that when caloric intake remains the same or slightly increased by adding nuts to habitual diet in free-living conditions or replaces a portion of the calories of baseline diets under controlled conditions, there 


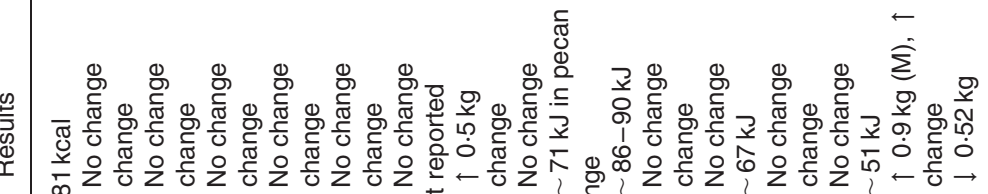

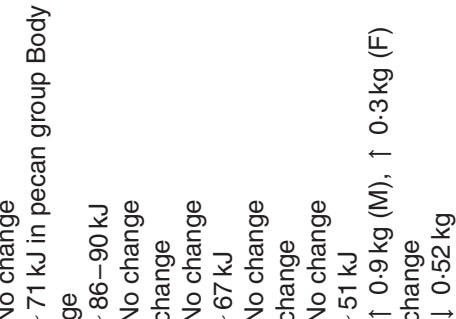

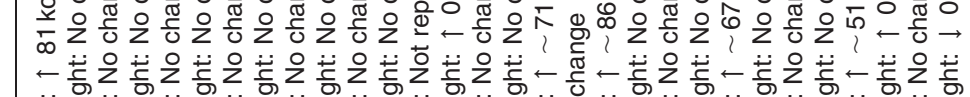

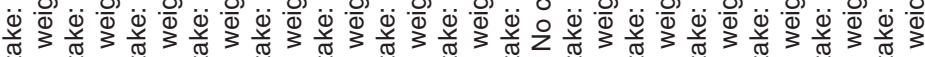

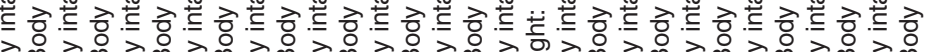

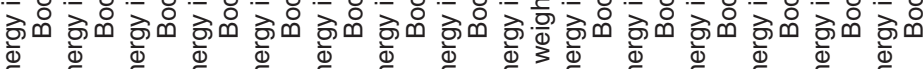

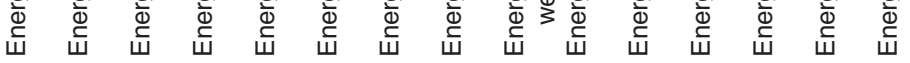

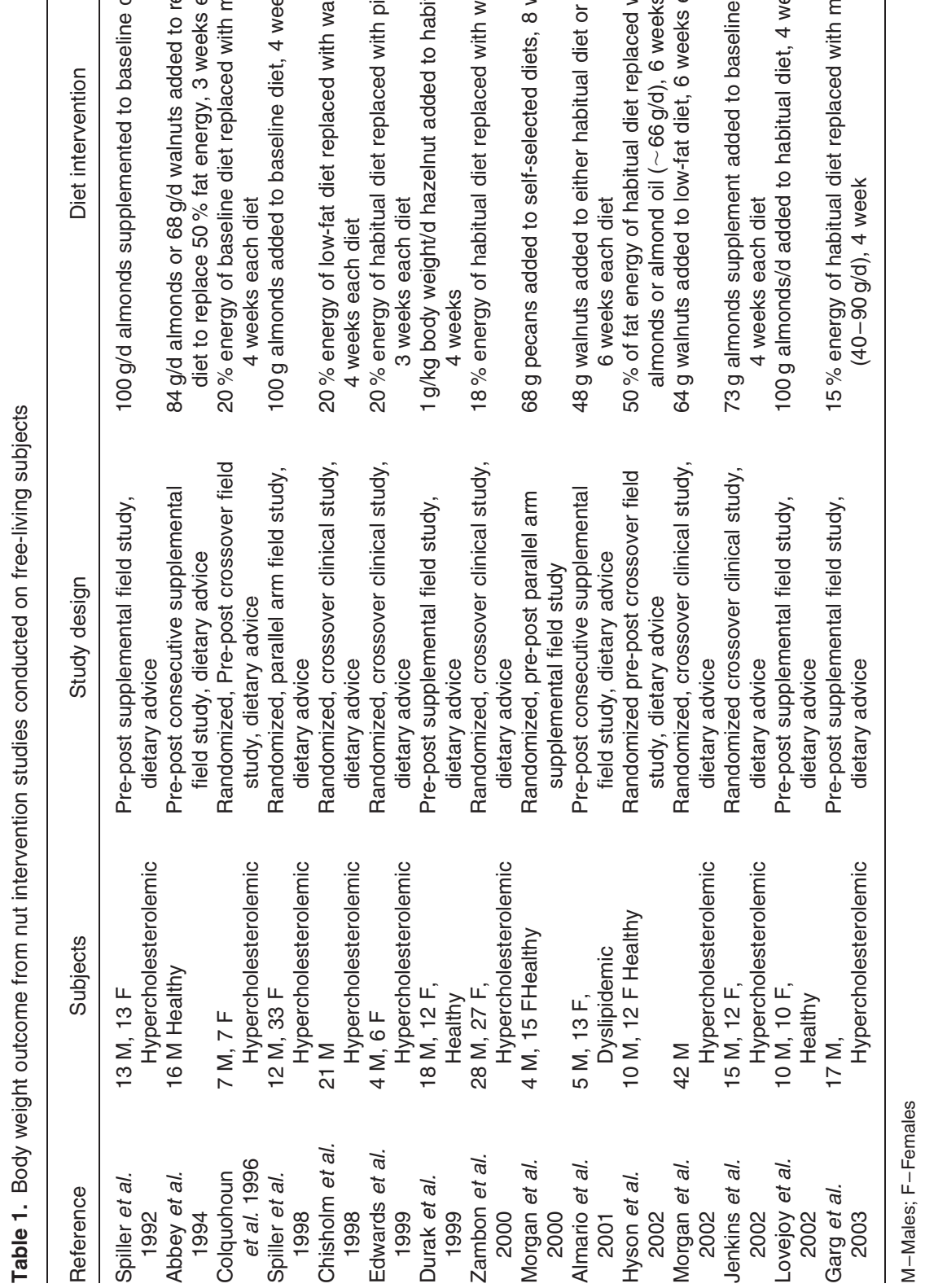


is no weight gain in healthy individuals and hypercholesterolemic patients. This is true either when the percent energy from fat after adding nuts remains the same (Sabaté et al. 1993) or is significantly increased (Rajaram et al. 2001; Sabaté et al. 2003).

\section{Nut feeding studies with body weight as primary outcome}

Three recent studies specifically investigated the effects on body weight of supplementing habitual diets with nuts in free-living subjects (Alper \& Mattes, 2002; Fraser et al. 2002; Sabaté et al. 2005). One of these studies was on peanuts (Alper \& Mattes, 2002), which although botanically classified as legumes, will be considered for discussion, since they are nutritionally very similar to tree nuts. In this study, $119 \mathrm{~kJ} / \mathrm{d}(500 \mathrm{kcal} / \mathrm{d})$ of peanut supplement was provided to fifteen adults with normal body weight. There were three phases to the study: the free-feeding phase in which subjects received peanuts without dietary guidance, an addition phase in which subjects were asked to add the peanuts to their habitual diet and a substitution phase in which they were asked to replace an equal amount of other fats in the diets for peanuts. During the substitution phase no weight gain was noted. In the free-feeding phase, subjects gained $1.0 \mathrm{~kg}$ during the 8 -week intervention which is considerably lower than the predicted $3.6 \mathrm{~kg}$ based on the additional calories coming from the peanuts. Also, during the addition phase, subjects gained $0.6 \mathrm{~kg}$ as opposed to the $1.4 \mathrm{~kg}$ which was predicted. Part of this difference is attributed to the dietary compensation for a portion of the extra calories coming from peanuts. An increase in resting energy expenditure of $11 \%$ was noted after peanut consumption despite no changes in physical activity level.

Fraser et al. (2002) reported that 6 mo of almond supplementation had minimal effects on body weight. Eightyone subjects were provided with $42-70 \mathrm{~g}$ raw or dry-roasted almonds/d (averaging $76 \mathrm{~kJ}$ per person) with no instructions other than eating the almonds. Six months following nut supplementation, men gained $0.65 \mathrm{~kg}$ while women did not gain any significant weight (Table 2). Only lean subjects in the lowest tertile of baseline BMI gained weight and obese women (highest tertile of baseline BMI) actually lost weight during almond supplementation. The average body weight increase for subjects during almond supplementation was $0.4 \mathrm{~kg}$ while the predicted weight gain based on the extra calories consumed from almonds is $6.4 \mathrm{~kg}$. The physical activity

Table 2. Body weight changes after 6 months almond supplementation in free-living healthy subjects (mean values)

\begin{tabular}{lccr}
\hline Measurement & Control & Almonds & $P$ Value $^{*}$ \\
\hline Body weight $(\mathrm{kg})$ & & & \\
$\quad$ Males & 83.18 & 83.83 & $<0.01$ \\
$\quad$ Females & 69.13 & 69.40 & 0.79 \\
Waist/hip ratio & & & \\
Males & 0.943 & 0.955 & $<0.01$ \\
Females & 0.779 & 0.784 & 0.18 \\
\hline
\end{tabular}

*Paired $t$ test compares the means of the two diet periods. Adapted from Fraser et al. 2002. report showed no significant difference in frequency and vigour of activity during the two diet phases nor was there a difference in resting energy expenditure. However, food displacement was seen following almond supplementation, and approximately $54 \%$ (by 24-hour recalls) or $78 \%$ (from food diary) of the extra calories from almonds was displaced by a reduction of intake in other foods of the habitual diet (Jaceldo-Siegl et al. 2004).

In a recent walnut supplemented trial (Sabaté et al. 2005), ninety free-living men and women were assigned to either a walnut supplemented diet $(28-56 \mathrm{~g}$ walnuts/d) or habitual diet for 6 months each in a crossover fashion. Walnuts were supplemented to the habitual diets with no specific instructions other than to eat the allotted amount. The walnut supplementation caused an increase in daily energy intake of $557 \mathrm{~kJ}$ $(133 \mathrm{kcal})$. Although this should have led to a weight gain of $3.1 \mathrm{~kg}$ over the 6 months, the observed increases in body weight was $0.4 \mathrm{~kg}$, in BMI $0.2 \mathrm{~kg} / \mathrm{m}^{2}$ and in fat mass $0.2 \mathrm{~kg}$. In fact, this small increase in body weight with the walnut supplement was not significant when energy differences between the two diets were controlled for. These findings confirm that adding nuts to habitual diets does not adversely affect body weight.

\section{Nut supplement in the context of weight loss diets}

There have been two trials so far that have looked at the efficacy of nuts in the context of weight loss diets. In one study (McManus et al. 2001), 101 overweight subjects received either a low fat (20\% energy from fat) or a moderate fat diet ( $35 \%$ energy from fat) containing several nuts, peanut butter and olive oil. Following an 18-month intervention, the moderate fat group experienced weight loss and decrease in waist circumference while the low fat group regained weight progressively. After $2 \frac{1}{2}$ years, the moderate fat group still weighed significantly less than the low fat group.

In a weight reduction study (Wien et al. 2003), sixty-five overweight and obese individuals were randomized into either a complex carbohydrate enriched or an almond enriched low calorie diets for 24 weeks under free-living condition. Approximately $84 \mathrm{~g} / \mathrm{d}$ of almonds was provided to the almond enriched diet group, which was equivalent to $39 \%$ energy from fat as opposed to $18 \%$ energy from fat in the carbohydrate enriched low calorie diet. As expected, both diet groups lost weight (Fig. 2), but the almond group experienced a sustained and $62 \%$ greater weight reduction for the 24-week duration than the carbohydrate group. The almond group also had a $50 \%$ greater decrease in waist circumference and a $62 \%$ decrease in fat mass than the carbohydrate group. This study suggests that in the context of low caloric diets, including nuts may enhance weight loss and improve body composition indices. Additional benefits for nuts included in weight loss diets are that it may provide for variety in texture, contribute to satiety and improve long-term compliance.

\section{Potential mechanisms}

From the epidemiological studies we note an inverse relationship between nut consumption and body weight. Since nuts are 


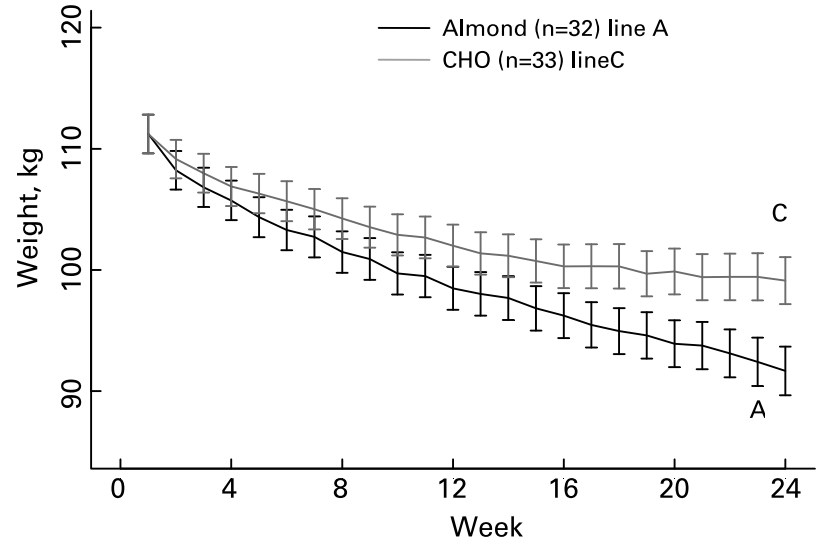

Fig. 2. Body weight loss on a calorie restricted diet with almond or carbohydrate supplement. Almond - Low calorie almond diet; CHO - Low calorie carbohydrate diet. Reproduced with permission from Wien et al. (2003).

a high fat, high energy food, it is possible that obese individuals avoid them while lean individuals include them more freely and this may result in the observed negative association between nut intake and body weight. It is also likely that those eating nuts frequently practice other healthy lifestyle habits, such as increased physical activity. In fact, nut consumption was associated with greater frequency of vigorous exercise among participants of the Nurses Health Study (Hu et al. 1998). The Physicians' Health Study also showed that men who ate nuts frequently were also more physically active (Albert et al. 2002). However, this was not substantiated in an intervention study where almonds were supplemented to the habitual diets of free-living subjects for 6 months. No change in exercise frequency and vigour was observed (US Department of Agriculture \& Agricultural Research Service, 2000) in this study.

Several mechanisms can potentially explain why nuts do not cause weight gain. Nuts are energy dense foods with high fibre, protein and low glycaemic index, all of which are dietary factors that have been shown to increase satiety (Holt et al. 1995). In the 6-month almond supplemented study (Fraser et al. 2002), 54-78\% of the extra energy from almonds was displaced by reductions in other foods suggesting a satiety effect. Nuts are high in unsaturated fatty acids and hence may influence diet-induced thermogenesis by increasing resting energy expenditure. Both animal and human studies have shown that unsaturated fat increases fat oxidation because of higher diet-induced thermogenesis resulting in less body fat accumulation (van Marken Lichtenbelt et al. 1997). While peanut supplementation for 19 weeks resulted in an $11 \%$ increase in resting energy expenditure (Alper \& Mattes, 2002), daily almond supplementation for 6 months did not change resting energy expenditure (Fraser et al. 2002).

Given that nuts are a complex matrix of nutrients, it is likely that fatty acid availability from nuts is decreased from incomplete digestion and or absorption. An earlier study with peanuts showed that $76 \mathrm{~g}$ peanuts consumed for 4-6 days resulted in $17 \%$ excretion of dietary fat in stools (Alper \& Mattes, 2002). Visual inspection showed that stools contained intact portions of the nuts indicating that absorption was compromised. In an intervention feeding trial with pecans, we demonstrated that stool fat increased $(25 \mathrm{~g} / \mathrm{d})$ when subjects were on the nut diet compared to the control diet $(6 \mathrm{~g} / \mathrm{d})$. This represented 8 and $3 \%$ of the dietary fat of the pecan and control diet, respectively (Zemaitis \& Sabaté, 2001). A similar observation was made when the intervention food was almonds, although the percent fat loss in stools was much less (4\%) than on the pecan or peanut diets. Recently Ellis et al. (2004) systematically looked at the bioavailability of fatty acids from almonds by simulating chewing action and following up with a digestibility study. They demonstrated that the mechanical disruption of almond tissue or the chewing process damaged only the first layer of cells of the almond resulting in an incomplete release of the fatty acids. Further, consumption of $100-200 \mathrm{~g} / \mathrm{d}$ of almonds by healthy volunteers caused a 3 -fold increase in percent faecal fat excretion compared to when they ate a nut free diet. Electron microscopy revealed intact cell walls in the faecal samples that had resisted digestion and thus retained some of the intracellular fatty acids contained in the almonds.

Thus, the excretion of fat in the stools and the displacement of foods from habitual diets together may account for the lack of weight gain among nut eaters. Future studies need to further explore the mechanism(s) by which nuts prevent weight gain or in some cases induce weight loss.

\section{Nuts and insulin resistance/type-2 diabetes}

\section{Epidemiological evidence}

A prospective cohort study of women (Jiang et al. 2002) found that the frequency of nut consumption had a substantial and highly significant inverse association with risk of type-2 diabetes. The reduction in risk of developing type-2 diabetes was $30 \%$ lower in those consuming nuts five or more times per week and $20 \%$ lower in those consuming nuts 1-4 times a week compared to those that almost never ate nuts (Table 3). The inverse association persisted even after adjusting for other known risk factors including age, obesity, physical activity, smoking, family history and other dietary factors.

The protective effect of nut consumption on incidence of type-2 diabetes was consistent among various subgroups in women. The frequency of nut consumption was significantly and inversely related to the risk of type- 2 diabetes in both multivitamin users and non-users, those above or below mean body mass index, and in those that consumed a high or low glycaemic load. Similar findings were also noted for the consumption of peanut butter. However, whether a similar relationship will be observed in men remains to be determined in future studies.

To date, this is the only study that has looked at the association between nut intake and risk of diabetes although previously, unsaturated fat intake has been shown to reduce the risk of type-2 diabetes and improve glycaemic control in diabetic patients (Hu et al. 2001).

\section{Intervention studies}

In a randomized, double-blind crossover study (Lovejoy et al. 2002), 34 men and women with type- 2 diabetes were assigned 
Table 3. Relative risks of type 2 diabetes in women according to frequency of nut consumption

\begin{tabular}{|c|c|c|c|c|c|}
\hline & \multicolumn{5}{|c|}{ Frequency of nut consumption ( $28 \mathrm{~g}$ serving) } \\
\hline & Never/almost never & $<$ Once/week & $1-4$ times /week & $\geq 5$ times/week & $P$ for trend \\
\hline Person-years & 441.007 & 466.464 & $309 \cdot 608$ & $66 \cdot 468$ & - \\
\hline Age-adjusted RR $(95 \% \mathrm{Cl})$ & 1.00 & $0.82(0.76-0.89)$ & $0.69(0.63-0.76)$ & $0.55(0.45-0.66)$ & $<0.001$ \\
\hline Age- and BMI-adjusted RR (95\% Cl) & 1.00 & $0.91(0.84-0.99)$ & $0.83(0.75-0.91)$ & $0.74(0.61-0.89)$ & $<0.001$ \\
\hline Multivariate RR $(95 \% \mathrm{Cl})^{*}$ & 1.00 & $0.92(0.85-1.00)$ & $0.84(0.76-0.93)$ & $0.73(0.60-0.89)$ & $<0.001$ \\
\hline
\end{tabular}

$\mathrm{RR}$, Relative risk; $\mathrm{BMI}$, Body mass index; $\mathrm{Cl}$, Confidence interval.

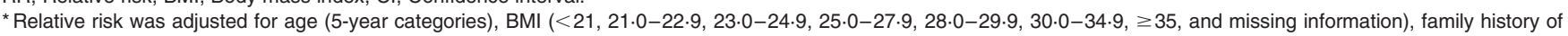
diabetes in a first-degree relative (yes or no), moderate/vigorous exercise $(<1,1,2-3,4-6, \geq 7 \mathrm{~h} /$ week), cigarette smoking (never, past, or current smoking of $1-14,15-24$ or $\geq 25$ cigarettes/d), alcohol consumption $(0,0 \cdot 1-5 \cdot 0,5 \cdot 1-15 \cdot 0$ or $>15 \mathrm{~g} / \mathrm{d})$, and total energy intake. Reproduced with permission from Jiang et al. 2002 .

to one of four different diets: high fat-high almond diet, low fat-high almond diet, high fat-control diet and low fat-control diet for 4 weeks each. The fat source in the low fat and high fat control diets was olive or canola oil. The almond enriched diets used $10 \%$ of energy from almonds ( $~ 85 \mathrm{~g}$ almonds/ $619 \mathrm{~kJ}$ diet). In this study no significant effect of fat amount or source was seen on plasma glucose and insulin levels during a 2-h oral glucose tolerance test. The almond enriched high fat diet had a favourable effect on serum total cholesterol without adversely affecting glycaemia. It is likely that nut intervention longer than 4 weeks and greater than $10 \%$ of total energy intake is required to modify insulin sensitivity and glycaemic control. Similarly, $30 \mathrm{~g}$ a day of walnuts added to the low-fat diet of type- 2 diabetic patients improved blood lipid profiles by specifically increasing HDL-C/total-C ratio without adversely affecting glycosylated haemoglobin levels and body weight (Tapsell et al. 2004).

More recently, sixty-five overweight subjects (37 women, 28 men) completed a randomized dietary intervention trial for 24 weeks to determine the efficacy of an almond-based hypocaloric diet on dyslipidemia, insulin resistance and weight changes (Wien et al. 2003). Seventy percent of the participants had type-2 diabetes and the remainder had insulin resistant syndrome. Upon being selected, all participants followed a 2-week run-in period with no intervention apart from a multivitamin/mineral supplement. At the end of the 2 weeks, participants were randomized based on gender and presence or absence of type- 2 diabetes into a formula-based low caloric diet supplemented with either almonds $(84 \mathrm{~g} / \mathrm{d}$ per $238 \mathrm{~kJ}$ ) or complex carbohydrates equivalent in calories for 24 weeks.

There was a $54 \%$ reduction in fasting insulin levels in the almond supplemented group compared to the carbohydrate diet group (Table 4). Insulin resistance as measured by the homeostasis model analysis (HOMA-IR) was decreased significantly in both diet groups, but an improved beta cell function was only observed on the almond diet. Among subjects with type-2 diabetes, diabetes medication reduction was either sustained or reduced further in $96 \%$ of the almond supplemented group compared to only $50 \%$ among the carbohydrate supplemented group. There was also a significant increase in ketosis in the almond group indicating a greater fat oxidation which probably accounts for the greater magnitude of weight loss seen with almond supplementation. Thus, there is some evidence to suggest that almonds, and perhaps other nuts, may have a favourable effect on insulin sensitivity. More studies are needed to support these observations.

\section{Potential mechanism of action}

The fatty acid composition of nuts may play a role in modifying insulin resistance, and therefore, the risk for type-2 diabetes. In fact, specific types of fatty acids are better predictors of the risk of type-2 diabetes than total dietary fat intake (Hu et al. 2001). A higher intake of n-3 PUFA is associated with lower risk of type- 2 diabetes whereas a higher intake of saturated and trans fatty acid intake adversely affects glycaemic control thereby increasing the risk of type-2 diabetes (Hu et al. 2001; Vessby et al. 2001). The mechanisms by which specific fatty acids affect insulin sensitivity are not clearly understood. However, it has been shown that the fatty acid composition of the phospholipids in the skeletal muscle cell membranes is directly related to insulin sensitivity in humans. A specific fatty acid in cell membranes could influence insulin action through altering insulin receptor binding or affinity and influencing ion permeability and cell signalling (Storlien et al. 1996). Monounsaturated fatty acids are also known to improve beta cell efficiency through enhanced

Table 4. Body weight and insulin sensitivity measures on two weight loss diets (least square mean values with their standard error)

\begin{tabular}{|c|c|c|c|}
\hline Measurement & Week & Almond-LCD & Carbohydrate-LCD \\
\hline \multirow[t]{2}{*}{ Weight (kg) } & 0 & $111.3(0.82)$ & $111 \cdot 2(0.82)^{\star \star *}$ \\
\hline & 24 & $201.7(2 \cdot 3)$ & $218 \cdot 1(2 \cdot 2)$ \\
\hline \multirow{2}{*}{ BMI $\left(k g / m^{2}\right)$} & 0 & $38.3(0.3)$ & $38.4(0.3)^{\star \star \star}$ \\
\hline & 24 & $31.6(0.3)$ & $34.2(0.3)$ \\
\hline \multirow[t]{2}{*}{ Fat mass (kg) } & 0 & $46.6(1.0)$ & $46.4(1.0)^{\star}$ \\
\hline & 24 & $32.5(1.1)$ & $37 \cdot 3(1 \cdot 1)$ \\
\hline \multirow[t]{2}{*}{ Fat free mass $(\mathrm{kg})$} & 0 & $62.7(0.63)$ & $62.4(0.63)$ \\
\hline & 24 & $57.6(0.72)$ & $60.0(0.72)$ \\
\hline \multirow[t]{2}{*}{ Insulin ( $\mu \mathrm{U} / \mathrm{ml})$} & 0 & $46(5)$ & $47(5)$ \\
\hline & 24 & $21(5)$ & $32(5)$ \\
\hline \multirow[t]{2}{*}{ Glucose (mg/dL) } & 0 & $152(11)$ & $152(11)$ \\
\hline & 24 & $128(11)$ & $127(11)$ \\
\hline \multirow[t]{2}{*}{ HOMA-IR } & 0 & $20(4)$ & $17(4)^{\star \star}$ \\
\hline & 24 & $7(2)$ & 11(2) \\
\hline \multirow[t]{2}{*}{ Ketone (mmol/L) } & 0 & $0.10(0.04)$ & $0.11(0.03)^{\star *}$ \\
\hline & 24 & $0.36(0.05)$ & $0.11(0.05)$ \\
\hline
\end{tabular}

LCD, Low calorie diet. HOMA-IR, Homeostasis model analysis to measure insulin sensitivity. ${ }^{* \star *}(P<0.0001),{ }^{* *}(P<0.02)$ and ${ }^{*}(P<0.05)$ Statistically significant differences between groups. Adapted and reproduced with permission from Wien et al. 2003. 
Table 5. Nutritional composition (per $100 \mathrm{~g}$ edible portion) of some selected tree nuts*

\begin{tabular}{|c|c|c|c|c|c|c|c|}
\hline Nutrient & Walnut & Almond & Pecan & Macadamia & Pistachio & Cashew & Hazelnut \\
\hline Energy (kcal) & 654 & 578 & 691 & 718 & 557 & 566 & 628 \\
\hline Protein (g) & $15 \cdot 2$ & $21 \cdot 3$ & $9 \cdot 2$ & 7.9 & $20 \cdot 6$ & $18 \cdot 2$ & $15 \cdot 0$ \\
\hline Carbohydrate (g) & $13 \cdot 7$ & $19 \cdot 7$ & $13 \cdot 9$ & $13 \cdot 8$ & $28 \cdot 0$ & $27 \cdot 1$ & $16 \cdot 7$ \\
\hline Fat $(g)$ & 65. & $50 \cdot 6$ & 71.9 & $75 \cdot 8$ & $44 \cdot 4$ & $46 \cdot 9$ & $60 \cdot 8$ \\
\hline Saturated (g) & $6 \cdot 1$ & 3.9 & $6 \cdot 2$ & $12 \cdot 1$ & $5 \cdot 4$ & $8 \cdot 3$ & 4.5 \\
\hline MUFA $(\mathrm{g})$ & $8 \cdot 9$ & $32 \cdot 2$ & $40 \cdot 8$ & 58.9 & $23 \cdot 3$ & 25.5 & $45 \cdot 7$ \\
\hline PUFA (g) & $47 \cdot 2$ & $12 \cdot 2$ & $21 \cdot 6$ & 1.5 & $13 \cdot 5$ & $8 \cdot 4$ & $7 \cdot 9$ \\
\hline Fiber (g) & 6.7 & $11 \cdot 8$ & $9 \cdot 6$ & 8.6 & $10 \cdot 3$ & 3.3 & 9.7 \\
\hline Magnesium (mg) & 158 & 275 & 121 & 130 & 121 & 292 & 163 \\
\hline$\propto-$-tocopherol (mg) & $2.9^{a}$ & $26 \cdot 2$ & $4 \cdot 1^{\mathrm{a}}$ & 0.6 & 4.6 & 1.5 & $15 \cdot 2$ \\
\hline Lysine: Arginine & 0.2 & 0.3 & 0.3 & 0.4 & 0.6 & 0.5 & 0.2 \\
\hline Copper (mg) & $1 \cdot 0$ & 0.9 & $1 \cdot 2$ & 0.3 & $1 \cdot 2$ & $2 \cdot 2$ & 1.5 \\
\hline
\end{tabular}

* Source: United States Department of Agriculture Nutrient Database for Standard Reference, Release August 2005. ${ }^{\mathrm{a}} \gamma$-tocophero in walnuts is $17.2 \mathrm{mg}$, in pecans is $19.1 \mathrm{mg}$.

secretion of glucagon-like peptide-1 that is known to help in regulating postprandial glucose clearance and insulin sensitivity (Rocca et al. 2001).

In addition to the type of fatty acid in nuts, the non-lipid components of nuts (Table 5) may also contribute towards lowering the risk of type-2 diabetes. Several prospective studies (Paolisso et al. 1990; Salmeron et al. 1997) have shown that the risk of type-2 diabetes is lowered with higher intakes of fibre and magnesium and the inclusion of low glycaemic index foods. As reviewed by Salas-Salvadó et al. (2006) in this supplement, nuts provide a significant amount of fibre $(\sim 4-12 \mathrm{~g} / 100 \mathrm{~g})$. They are also considered a good source of magnesium $(\sim 120-300 \mathrm{mg} / 100 \mathrm{~g})$, and magnesium intake is inversely associated with diabetes risk (Lopez-Ridaura et al. 2004). Being a whole food, it is reasonable to expect synergistic interaction between many of the nutrients and non-nutrients in nuts as they work to influence insulin resistance and, therefore, the risk of type-2 diabetes.

\section{Conclusions}

Although nuts are high in fat, the available data demonstrate that adding nuts to habitual diets of free-living individuals does not cause weight gain. In fact, there may be a tendency for nuts to decrease fat mass. As expected, isoenergetic replacement of nuts for other foods does not result in changes in body weight. In the context of weight loss diets, adding nuts to a calorie-restricted diet in obese individuals produces a greater magnitude of weight loss. Studies over 1 year are required to prove the safety of consuming nuts under freeliving conditions in the long-term.

New research is also pointing to a protective role for nuts in reducing the risk of type- 2 diabetes and in improving insulin sensitivity in obese diabetics under weight loss situation. Clearly more research is needed in determining whether nuts do influence insulin sensitivity in both normal and type-2 diabetic individuals. Future studies on the role of nuts on body weight regulation and insulin sensitivity should attempt to understand the mechanism(s) by which nuts bring out the desirable effects. In the meanwhile, there is sufficient evidence to continue promoting the inclusion of nuts as part of healthy diets.

\section{References}

Abbey M, Noakes M, Belling GB \& Nestel PJ (1994) Partial replacement of saturated fatty acids with almonds or walnuts lowers total plasma cholesterol and low-density-lipoprotein cholesterol. Am J Clin Nutr 59, 995-999.

Albert CM, Gaziano JM, Willett WC \& Manson JE (2002) Nut consumption and decreased risk of sudden cardiac death in the Physicians' Health Study. Arch Intern Med 162, 1382-1387.

Almario RU, Vonghavaravat V, Wong R \& Kasim-Karakas SE (2001) Effects of walnut consumption on plasma fatty acids and lipoproteins in combined hyperlipidemia. Am J Clin Nutr 74, 72-79.

Alper CM \& Mattes RD (2002) Effects of chronic peanut consumption on energy balance and hedonics. Int $J$ Obes Relat Metab Disord 26, 1129-1137.

Chisholm A, Mann J, Skeaff M, Frampton C, Sutherland W, Duncan A \& Tiszavari S (1998) A diet rich in walnuts favourably influences plasma fatty acid profile in moderately hyperlipidaemic subjects. Eur J Clin Nutr 52, 12-16.

Colquhoun DM, Humphries JA, Moores D \& Somerset SM (1996) Effects of a macadamia nut enriched diet on serum lipids and lipoproteins compared to a low fat diet. Food Aus 48, 216-222.

Curb JD, Wergowske G, Dobbs JC, Abbott RD \& Huang B (2000) Serum lipid effects of a high-monounsaturated fat diet based on macadamia nuts. Arch Intern Med 160, 1154-1158.

Durak I, Koksal I, Kacmaz M, Buyukkocak S, Cimen BM \& Ozturk HS (1999) Hazelnut supplementation enhances plasma antioxidant potential and lowers plasma cholesterol levels. Clin Chim Acta 284, 113-115.

Edwards K, Kwaw I, Matud J \& Kurtz I (1999) Effect of pistachio nuts on serum lipid levels in patients with moderate hypercholesterolemia. J Am Coll Nutr 18, 229-232.

Ellis PR, Kendall CW, Ren Y, Parker C, Pacy JF, Waldron KW \& Jenkins DJ (2004) Role of cell walls in the bioaccessibility of lipids in almond seeds. Am J Clin Nutr 80, 604-613.

Fraser GE, Bennett HW, Jaceldo KB \& Sabate J (2002) Effect on body weight of a free 76 Kilojoule (320 calorie) daily supplement of almonds for six months. J Am Coll Nutr 21, 275-283.

Fraser GE, Sabaté J, Beeson WL \& Strahan TM (1992) A possible protective effect of nut consumption on risk of coronary heart disease. The Adventist Health Study. Arch Intern Med 152, 1416-1424.

Garcia-Lorda P, Megias Rangil I \& Salas-Salvado J (2003) Nut consumption, body weight and insulin resistance. Eur J Clin Nutr 57, Suppl. 1, S8-S11.

Garg ML, Blake RJ \& Wills RB (2003) Macadamia nut consumption lowers plasma total and LDL cholesterol levels in hypercholesterolemic men. J Nutr 133, 1060-1063. 
Holt SH, Miller JC, Petocz P \& Farmakalidis E (1995) A satiety index of common foods. Eur J Clin Nutr 49, 675-690.

Hu FB, Stampfer MJ, Manson JE, Rimm EB, Colditz GA, Rosner BA, Speizer FE, Hennekens CH \& Willett WC (1998) Frequent nut consumption and risk of coronary heart disease in women: prospective cohort study. BMJ 317, 1341-1345.

Hu FB, van Dam RM \& Liu S (2001) Diet and risk of Type II diabetes: the role of types of fat and carbohydrate. Diabetologia $\mathbf{4 4}$, $805-817$.

Hyson DA, Schneeman BO \& Davis PA (2002) Almonds and almond oil have similar effects on plasma lipids and LDL oxidation in healthy men and women. $J$ Nutr 132, 703-707.

Iwamoto M, Imaizumi K, Sato M, Hirooka Y, Sakai K, Takeshita A \& Kono M (2002) Serum lipid profiles in Japanese women and men during consumption of walnuts. Eur J Clin Nutr 56, 629-637.

Jaceldo-Siegl K, Sabate J, Rajaram S \& Fraser GE (2004) Long-term almond supplementation without advice on food replacement induces favourable nutrient modifications to the habitual diets of free-living individuals. Br J Nutr 92, 533-540.

Jenkins DJ, Kendall CW, Marchie A, Parker TL, Connelly PW, Qian W, Haight JS, Faulkner D, Vidgen E, Lapsley KG \& Spiller GA (2002) Dose response of almonds on coronary heart disease risk factors: blood lipids, oxidized low-density lipoproteins, lipoprotein(a), homocysteine, and pulmonary nitric oxide: a randomized, controlled, crossover trial. Circulation 106, 1327-1332.

Jiang R, Manson JE, Stampfer MJ, Liu S, Willett WC \& Hu FB (2002) Nut and peanut butter consumption and risk of type 2 diabetes in women. JAMA 288, 2554-2560.

Krauss RM, Eckel RH, Howard B, Appel LJ, Daniels SR, Deckelbaum RJ, Erdman JW Jr, Kris-Etherton P, Goldberg IJ, Kotchen TA, Lichtenstein AH, Mitch WE, Mullis R, Robinson K, WylieRosett J, St Jeor S, Suttie J, Tribble DL \& Bazzarre TL (2000) AHA Dietary Guidelines: revision 2000: A statement for healthcare professionals from the Nutrition Committee of the American Heart Association. Circulation 102, 2284-2299.

Kushi LH, Folsom AR, Prineas RJ, Mink PJ, Wu Y \& Bostick RM (1996) Dietary antioxidant vitamins and death from coronary heart disease in postmenopausal women. $N$ Engl J Med 334, 1156-1162.

Lopez-Ridaura R, Willett WC, Rimm EB, Liu S, Stampfer MJ, Manson JE \& Hu FB (2004) Magnesium intake and risk of type 2 diabetes in men and women. Diabetes Care 27, 134-140.

Lovejoy JC, Most MM, Lefevre M, Greenway FL \& Rood JC (2002) Effect of diets enriched in almonds on insulin action and serum lipids in adults with normal glucose tolerance or type 2 diabetes. Am J Clin Nutr 76, 1000-1006.

McManus K, Antinoro L \& Sacks F (2001) A randomized controlled trial of a moderate-fat, low-energy diet compared with a low fat, low-energy diet for weight loss in overweight adults. Int $J$ Obes Relat Metab Disord 25, 1503-1511.

Morgan JM, Horton K, Reese D, Carey C, Walker K \& Capuzzi DM (2002) Effects of walnut consumption as part of a low-fat, lowcholesterol diet on serum cardiovascular risk factors. Int $J$ Vitam Nutr Res 72, 341-347.

Morgan WA \& Clayshulte BJ (2000) Pecans lower low-density lipoprotein cholesterol in people with normal lipid levels. $J$ Am Diet Assoc 100, 312-318.

Paolisso G, Scheen A, D’Onofrio F \& Lefebvre P (1990) Magnesium and glucose homeostasis. Diabetologia 33, 511-514.

Rajaram S, Burke K, Connell B, Myint T \& Sabate J (2001) A monounsaturated fatty acid-rich pecan-enriched diet favorably alters the serum lipid profile of healthy men and women. J Nutr 131, $2275-2279$.

Rocca AS, LaGreca J, Kalitsky J \& Brubaker PL (2001) Monounsaturated fatty acid diets improve glycemic tolerance through increased secretion of glucagon-like peptide-1. Endocrinology 142, $1148-1155$.
Sabaté J (1993) Does nut consumption protect against ischaemic heart disease? Eur J Clin Nutr 47, Suppl. 1, S71-S75.

Sabaté J (2003) Nut consumption and body weight. Am J Clin Nutr 78, 647S-650S.

Sabaté J, Cordero-Macintyre Z, Siapco G, Torabian S \& Haddad E (2005) Does regular walnut consumption lead to weight gain? $\mathrm{Br}$ $J$ Nutr 94, 859-864.

Sabaté J, Fraser GE, Burke K, Knutsen SF, Bennett H \& Lindsted KD (1993) Effects of walnuts on serum lipid levels and blood pressure in normal men. $N$ Engl J Med 328, 603-607.

Sabaté J, Haddad E, Tanzman JS, Jambazian P \& Rajaram S (2003) Serum lipid response to the graduated enrichment of a Step I diet with almonds: a randomized feeding trial. Am J Clin Nutr 77, $1379-1384$.

Salas-Salvado J, Bullo M, Perez-Haras A \& Ros E (2006) Dietary Fibre, Nuts and Cardiovascular Disease. Br J Nutr, 96, Suppl. 2, S45-S51.

Salmeron J, Manson JE, Stampfer MJ, Colditz GA, Wing AL \& Willett WC (1997) Dietary fiber, glycemic load, and risk of non-insulin-dependent diabetes mellitus in women. JAMA 277, 472-477.

Schroder H, Marrugat J, Vila J, Covas MI \& Elosua R (2004) Adherence to the traditional mediterranean diet is inversely associated with body mass index and obesity in a spanish population. J Nutr 134, 3355-3361.

Soriguer FJ, Gonzalez-Romero S, Esteva I, Garcia-Arnes JA, Tinahones F, Ruiz de Adana MS, Olveira G, Mancha I \& Vazques F (1995) Does the intake of nuts and seeds alter the appearance of menarche? Acta Obstet Gynecol Scand 74, 455-461.

Spiller GA, Jenkins DA, Bosello O, Gates JE, Cragen LN \& Bruce B (1998) Nuts and plasma lipids: an almond-based diet lowers LDLC while preserving HDL-C. J Am Coll Nutr 17, 285-290.

Spiller GA, Jenkins DJ, Cragen LN, Gates JE, Bosello O, Berra K, Rudd C, Stevenson M \& Superko R (1992) Effect of a diet high in monounsaturated fat from almonds on plasma cholesterol and lipoproteins. J Am Coll Nutr 11, 126-130.

St-Onge MP (2005) Dietary fats, teas, dairy, and nuts: potential functional foods for weight control? Am J Clin Nutr 81, 7-15.

Storlien LH, Pan DA, Kriketos AD, O'Connor J, Caterson ID, Cooney GJ, Jenkins AB \& Baur LA (1996) Skeletal muscle membrane lipids and insulin resistance. Lipids 31, Suppl., S261-S265.

Tapsell LC, Gillen LJ, Patch CS, Batterham M, Owen A, Bare M \& Kennedy M (2004) Including walnuts in a low-fat/modified-fat diet improves HDL cholesterol-to-total cholesterol ratios in patients with type 2 diabetes. Diabetes Care 27, 2777-2783.

US Department of Agriculture \& Agricultural Research Service (2000). Continuing Survey of Food Intake by Individuals 199496 \& 1998. CSFFI CD-ROM.

van Marken Lichtenbelt WD, Mensink RP \& Westerterp KR (1997) The effect of fat composition of the diet on energy metabolism. Z Ernahrungswiss 36, 303-305.

Vessby B, Unsitupa M, Hermansen K, Riccardi G, Rivellese AA, Tapsell LC, Nalsen C, Berglund L, Louheranta A, Rasmussen BM, Calvert GD, Maffetone A, Pedersen E, Gustafsson IB \& Storlien LH (2001) Substituting dietary saturated for monounsaturated fat impairs insulin sensitivity in healthy men and women: The KANWU Study. Diabetologia 44, 312-319.

Wien MA, Sabate JM, Ikle DN, Cole SE \& Kandeel FR (2003) Almonds vs complex carbohydrates in a weight reduction program. Int J Obes Relat Metab Disord 27, 1365-1372.

Zambon D, Sabate J, Munoz S, Campero B, Casals E, Merlos M, Laguna JC \& Ros E (2000) Substituting walnuts for monounsaturated fat improves the serum lipid profile of hypercholesterolemic men and women. A randomized crossover trial. Ann Intern Med 132, 538-546.

Zemaitis J \& Sabaté J (2001) Effect of almond consumption on stool weight and stool fat. FASEB $J \mathbf{1 5}$, A602. 